\title{
Germinação de sementes e desenvolvimento de protocormos de Epidendrum secundum Jacq. (Orchidaceae) em associação com fungos micorrízicos do gênero Epulorhiza
}

\author{
Marlon Corrêa Pereira ${ }^{1}$, Denise Pereira Torres ${ }^{2}$, Fernanda Aparecida Rodrigues Guimarães ${ }^{3}$, \\ Olinto Liparini Pereira ${ }^{4}$ e Maria Catarina Megumi Kasuya ${ }^{5}$
}

Recebido em 4/11/2010. Aceito em 18/05/2011

\begin{abstract}
RESUMO
(Germinação de sementes e desenvolvimento de protocormos de Epidendrum secundum Jacq. (Orchidaceae) em associação com fungos micorrízicos do gênero Epulorhiza). Na natureza, as espécies de Orchidaceae estão associadas a fungos micorrízicos. A compreensão da especificidade fungo-planta nessa associação pode auxiliar no desenvolvimento de programas para propagação simbiótica das orquídeas. Fungos micorrízicos Epulorhiza spp. têm sido isolados de Epidendrum secundum Jacq. com maior freqüência. Assim, o objetivo deste trabalho foi avaliar a germinação de sementes e o desenvolvimento de protocormos de E. secundum associados a diferentes isolados de fungos do gênero Epulorhiza. Utilizou-se 16 fungos Epulorhiza spp. isolados de diferentes populações de E. secundum. Após 44 dias, todos os fungos testados induziram a germinação das sementes. Entretanto, observou-se diferença na eficiência desses fungos em promover o desenvolvimento dos protocormos, mesmo entre os fungos que apresentam semelhanças morfológicas. O estágio de desenvolvimento mais avançado dos protocormos e o maior índice de crescimento foram observados quando as sementes foram inoculadas com o isolado M65. Conclui-se que a germinação das sementes e o desenvolvimento dos protocormos de E. secundum dependem do fungo micorrízico e que, apesar da grande freqüência de associação entre essa espécie de orquídea e fungos do gênero Epulorhiza, é importante a seleção de isolados que apresentem maior eficiência simbiótica. Isolados eficientes são úteis na produção de mudas de orquídeas de importância econômica e ornamental e de espécies ameaçadas de extinção.
\end{abstract}

Palavras-chave: orquídea, fungos rizoctonióides, propagação simbiótica

\begin{abstract}
(Seed germination and protocorm development of Epidendrum secundum Jacq. (Orchidaceae) in association with Epulorhiza mycorrhizal fungi). In nature, species of Orchidaceae are always associated with mycorrhizal fungi. The comprehension of fungal-plant specificity in this association can assist with the establishment of programs that focus on symbiotic propagation of orchids. Epulorhiza mycorrhizal fungi have frequently been isolated from Epidendrum secundum Jacq. Thus, the objective of this study was to evaluate the germination of E. secundum seeds and protocorm development associated with different isolates of Epulorhiza spp. Sixteen Epulorhiza fungi obtained from different $E$. secundum populations were used. After 44 days, all isolates promoted seed germination of this species. However, differences were observed in the efficiency in promoting seed germination and protocorm development, even among the isolates that had morphological similarities. The highest stage of protocorm development and the highest growth indexes were obtained in the presence of isolate M65. The results suggest that seed germination and protocorm development of E. secundum depend on the mycorrhizal fungi and, despite the high frequency of association between this plant and Epulorhiza, it is important to select isolates with high efficiency to establish symbiosis. Efficient isolates are useful for the production of seedlings that have economic and ornamental importance, as well as for endangered orchids.
\end{abstract}

Key words: orchid, Rhizoctonia-like fungi, symbiotic propagation

\footnotetext{
1 Universidade Federal de Viçosa, Instituto de Ciências Biológicas e da Saúde, Rio Paranaíba, MG, Brasil

2 Universidade Federal de Viçosa, Viçosa, MG, Brasil

3 Universidade Federal de Viçosa, Departamento de Fitotecnia, Viçosa, MG, Brasil

4 Universidade Federal de Viçosa, Departamento de Fitopatologia, Viçosa, MG, Brasil

5 Universidade Federal de Viçosa, Departamento de Microbiologia, Viçosa, MG, Brasil

6 Autor para correspondência: marlon.pereira@ufv.br
} 


\section{Introdução}

As espécies de Orchidaceae apresentam sementes diminutas, desprovidas de tecido de reserva e dependentes da associação com fungos micorrízicos para obter as moléculas simples de carbono e os minerais necessários à germinação e ao desenvolvimento do embrião (Peterson et al. 2004; Dearnaley 2007). Mesmo quando desenvolve metabolismo autotrófico, a associação com o fungo se faz necessária principalmente para obtenção de minerais, tais como fósforo e nitrogênio, sendo possível evidenciar a transferência de carbono da planta para o fungo (Cameron et al. 2007; 2008).

Os pelotons, enovelados de hifas fúngicas formados no espaço intracelular de células parenquimáticas do embrião (Peterson et al. 2004) são as estruturas que caracterizam a interação orquídea - fungo micorrízico (Rasmussen 1995; Smith \& Read 1997). Por meio da degradação dos pelotons, o embrião, os protocormos e as raízes da orquídea obtêm o carbono e minerais necessários ao desenvolvimento da planta (Cameron et al. 2006; 2007).

A maioria dos fungos micorrízicos isolados de orquídeas é identificada como fungos semelhantes à Rhizoctonia ou rizoctonióides, sendo os principais gêneros Rhizoctonia, Ceratorhiza e Epulorhiza (Pereira et al. 2005a; b; Dearnaley 2007). Estes fungos estão dispersos nos ambientes naturais, exercendo outros papéis ecológicos como saprófitas, patógenos ou simbiontes de espécies vegetais de outras famílias (Rasmussen 2002). Estudos têm relatado a eficiência destes fungos em promover a germinação de sementes de orquídeas hospedeiras e não-hospedeiras na natureza (Zettler et al. 1999; Pereira et al. 2005c).

A especificidade, que pode ser definida como a amplitude filogenética dos fungos capazes de se associar com uma espécie de orquídea (Thompson 1994), é observada em diferentes níveis na associação

Fundo micorrízico - orquídea (Hadley \& Pegg 1989). Essa especificidade, somada às variações genéticas intraespecíficas da orquídea e do fungo e aos fatores abióticos como composição do substrato, temperatura, altitude e região geográfica, afetam diretamente o estabelecimento da associação micorrízica (Taylor \& Bruns 1999; Otero et al. 2005). Dessa forma, a co-inoculação de diferentes isolados fúngicos com sementes de uma orquídea pode resultar em diferentes porcentagens de germinação e estágios de desenvolvimento dos protocormos e plântulas (Pereira et al. 2005c).

A associação da planta com o fungo adequado é indispensável para a germinação das sementes, para o desenvolvimento do protocórmio e da plântula, de forma que a presença do parceiro fúngico é um fator importante na distribuição e desenvolvimento das orquídeas na natureza (Mckendrick et al. 2002; Peterson et al. 2004). Deste modo, a melhor compreensão da especificidade nesta associação é necessária para propagação simbiótica de mudas, tanto em programas para a reintrodução de espécies ameaçadas de extinção, como também para produção de mudas de orquídeas de interesse comercial (Pereira et al. 2002).

Epidendrum secundum Jacq. está compreendida na subfamília Epidendroideae, tribo Epidendreae, subtribo Laellinae (van den Berg et al. 2005; 2000; Freudenstein et al. 2004). É uma espécie de orquídea de hábito terrestre e/ou rupícola (Pinheiro \& Barros 2007). Apresenta floração durante todo o ano, o que, facilita sua identificação no campo. Os fungos do gênero Epulorhiza são os principais simbiontes dessa espécie em campos graminóides (Nogueira et al. 2005; Pereira et al. 2005a; 2009), tendo sido identificados três grupos de fungos Epulorhiza spp., morfologicamente distintos, associados a quatro populações de E. secundum (Pereira et al. 2009).

Deste modo, o objetivo deste trabalho foi avaliar a porcentagem de germinação das sementes de E. secundum e os estágios de desenvolvimento dos protocormos obtidos em co-inoculação com 16 isolados de Epulorhiza spp.

\section{Material e métodos}

Dezesseis fungos rizoctonióides Epulorhiza spp. (Tab. 1), pertencentes à Coleção de Fungos Micorrízicos de Orquídea do Laboratório de Associações Micorrízicas (Departamento de Microbiologia/ BIOAGRO/ UFV), foram utilizados no experimento. Esses fungos foram isolados de cinco diferentes populações de E. secundum, provenientes da Serra das Cabeças, sub-serra Totem Deitado (Licença Instituto Estadual de Floresta 050/05). Desses isolados, 14 pertenciam às populações I, II, III e IV e foram selecionados de forma a representar os três grupos morfológicos identificados por Pereira et al. (2009). Os outros dois isolados foram obtidos da população V de E. secundum (Tab.1).

Tabela 1. Populações da orquídea hospedeira (Epidendrum secundum), código dos isolados e os grupos morfológicos dos fungos Epulorhiza spp. utilizados na germinação simbiótica.

\begin{tabular}{lcc}
\hline Populações & Isolados & Grupos* $^{*}$ \\
\hline I & M52, M54, M58 & C \\
II & M61 & A \\
II & M62, M63 M64, M65, M67 & C \\
III & M69, M73, M74, M75 & B \\
IV & M76 & C \\
V & M77, M79 & $\mathrm{si}^{* *}$ \\
\hline
\end{tabular}

${ }^{\star}$ Grupos morfológicos identificados por Pereira et al. (2009). ${ }^{*}$ si: isolados não caracterizados morfologicamente em trabalhos anteriores.

Cápsulas maduras contendo sementes de E. secundum foram coletadas de plantas adultas naturais da sub-serra Totem Deitado. Em laboratório, as cápsulas foram armazenadas em envelopes de papel de filtro e mantidas em dessecador contendo sílica gel, à temperatura ambiente, até sua secagem, de forma a evitar sua deteriorazação e garantir o completo desenvolvimento dos embriões das sementes (Zettler et al. 1999). Após a secagem, foram mantidas a $4^{\circ} \mathrm{C}$, 
sendo abertas para coleta das sementes apenas no momento da montagem do experimento.

Amostras de sementes $(200 \mathrm{mg}$ ) de uma cápsula de $E$. secundum coletada da população II foram superficialmente desinfestadas por imersão em solução de hipoclorito de sódio a $20 \%$ (c.a. $0,5 \%$ de cloro ativo) por 10 minutos. Em seguida, foram lavadas por três vezes sucessivas, sob agitação constante, em água destilada esterilizada. As sementes desinfestadas foram mantidas imersas em $50 \mathrm{~mL}$ de água destilada estéril.

A suspensão de sementes foi submetida à agitação constante para homogeneização e, posteriormente, $400 \mu \mathrm{L}$ da suspensão foi aplicada sobre a superfície de cada placa de Petri contendo $20 \mathrm{~mL}$ de meio ágar aveia modificado (4 g.L $\mathrm{L}^{-1}$ de farelo de aveia, 7,5 g.L $\mathrm{L}^{-1}$ de ágar; $\mathrm{pH}$ 5,6) (Dixon 1987). Cada placa foi inoculada com um disco de $9 \mathrm{~mm}$ de diâmetro, contendo o micélio fúngico, retirado das bordas das colônias em crescimento em meio BDA (Batata Dextrose Ágar - $15 \mathrm{~g}$ de ágar, $15 \mathrm{~g}$ de glicose e $1 \mathrm{~L}$ de caldo de batata; pH 5,6). Placas contendo meio ágar aveia e sementes de E. secundum, sem inoculação do micélio, foram utilizadas como controle. As placas foram seladas com filme PVC e incubadas sob ausência de luz a $25^{\circ} \mathrm{C}$. Cinco repetições de cada tratamento foram distribuídas ao acaso na câmara de crescimento.

Após 44 dias foi realizada a avaliação do desenvolvimento dos protocormos, sob microscópio estereoscópico (Olympus SZ40). Aos diferentes estágios de desenvolvimento dos protocormos foram atribuídos valores de 0 a 6 , adaptados de Zettler \& Hofer (1998), sendo 0 = não ocorreu germinação; 1 = embrião bem desenvolvido dentro do envoltório e formação de rizóides; 2 = rompimento da testa; 3 = aparecimento do pró-meristema; 4 = início da formação da primeira folha, 5 = primeira folha bem desenvolvida e 6 = início da formação da segunda folha.

Os protocormos foram clareados e corados com azul de tripano (Phillips \& Hayman 1970). A formação dos pelotons, que caracterizam a associação simbiótica micorrízica em orquídeas, foi analisada por microscopia óptica (Olympus BX50), utilizando protocormos em diferentes estágios de desenvolvimento.

$\mathrm{O}$ número de protocormos nos diferentes estágios de germinação foi avaliado nas cinco repetições de cada isolado. A porcentagem de protocormos nos diferentes estágios de desenvolvimento, a porcentagem de germinação total e o índice de crescimento dos protocormos foram avaliados. A porcentagem de germinação total considerou os protocormos do estágio 2 até o estágio 6 para retirar da análise qualquer efeito da absorção de água pelo embrião, o que pode levar a respostas semelhantes às descritas para o estágio 1 . O índice de crescimento dos protocormos foi calculado utilizando a seguinte fórmula: $\mathrm{IC}=(\mathrm{N} 1+\mathrm{N} 2 \times 2+$ $\mathrm{N} 3 \times 3+\mathrm{N} 4 \times 4+\mathrm{N} 5 \times 5+\mathrm{N} 6 \times 6) \div(\mathrm{N} 0+\mathrm{N} 1+\mathrm{N} 2+\mathrm{N} 3+\mathrm{N} 4+\mathrm{N} 5$ $+\mathrm{N} 6$ ), onde $\mathrm{N} 0$ é o número de sementes no estágio $0, \mathrm{~N} 1$ o número de sementes no estágio 1 e assim até N6 (Otero et al. 2005). Esses cálculos foram realizados e os gráficos gerados utilizando o programa Microsoft Office Excel 2003. Os resultados foram expressos em média \pm desvio padrão.

\section{Resultados}

Os fungos do gênero Epulorhiza, isolados de Epidendrum secundum, induziram a germinação das sementes de E.secundum (Fig. 1). As sementes incubadas na ausência desses fungos não germinaram.

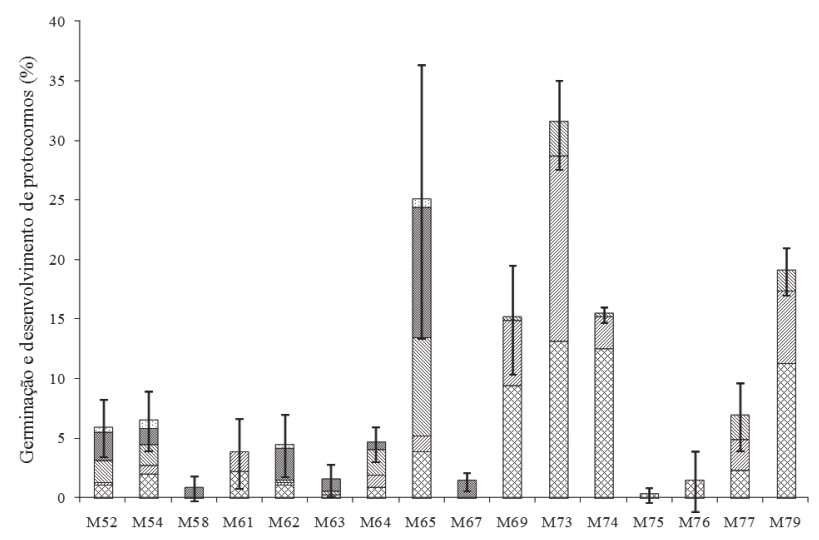

Figura 1. Porcentagem de germinação total e percentagem de protocormos de Epidendrum secundum nos diferentes estágios de desenvolvimento, determinada 44 dias após a inoculação de fungos rizoctonióides Epulorhiza spp. e cultivados

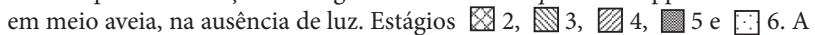
média da porcentagem de germinação total foi calculada considerando estágios de 2 a 6 . Os resultados estão apresentados em média \pm desvio padrão.

Os fungos isolados das populações I e II de E. secundum, com exceção do isolado M61, estimularam os protocormos a atingir os estágios mais avançados de desenvolvimento, sendo observado, pelo menos, a formação da primeira folha, no estágio 5 (Fig. 1, 2A-D). Em associação com o isolado M61, o desenvolvimento dos protocormos foi até formação do pró-meristema, no estágio 3 (Fig. 1).

Quando as sementes foram inoculadas com os isolados M69, M73 e M74 (população III), e os isolados M77 e M79 (população V), houve desenvolvimento dos protocormos até o início da formação da primeira folha (Fig. 1, 2F). O quarto isolado da população III, M75, e o isolado M76 da população IV, promoveram o desenvolvimento dos protocormos apenas até a formação do pró-meristema (Fig. 1).

Após 44 dias, os isolados M65 e M73 apresentaram as maiores porcentagens de germinação das sementes $(25$ e $31 \%$, respectivamente) e os maiores índices de crescimento (1,1 e 0,9 , respectivamente) (Fig. 1, 2, 3). O maior índice de crescimento de M65 se deve ao fato de ter produzido os estágios de desenvolvimento mais avançados: $11 \%$ de protocormos no estágio 5 e $0,8 \%$ no estágio 6 (Fig. 1, 2D, 3). Por outro lado, M73 promoveu o desenvolvimento dos protocormos apenas até o estágio 4 (3\%) (Fig. 1, 2E, 3).

Entre os isolados que apresentaram porcentagem de germinação entre 15 e 20\%, o estágio de desenvolvimento 
$\mathbf{A}$
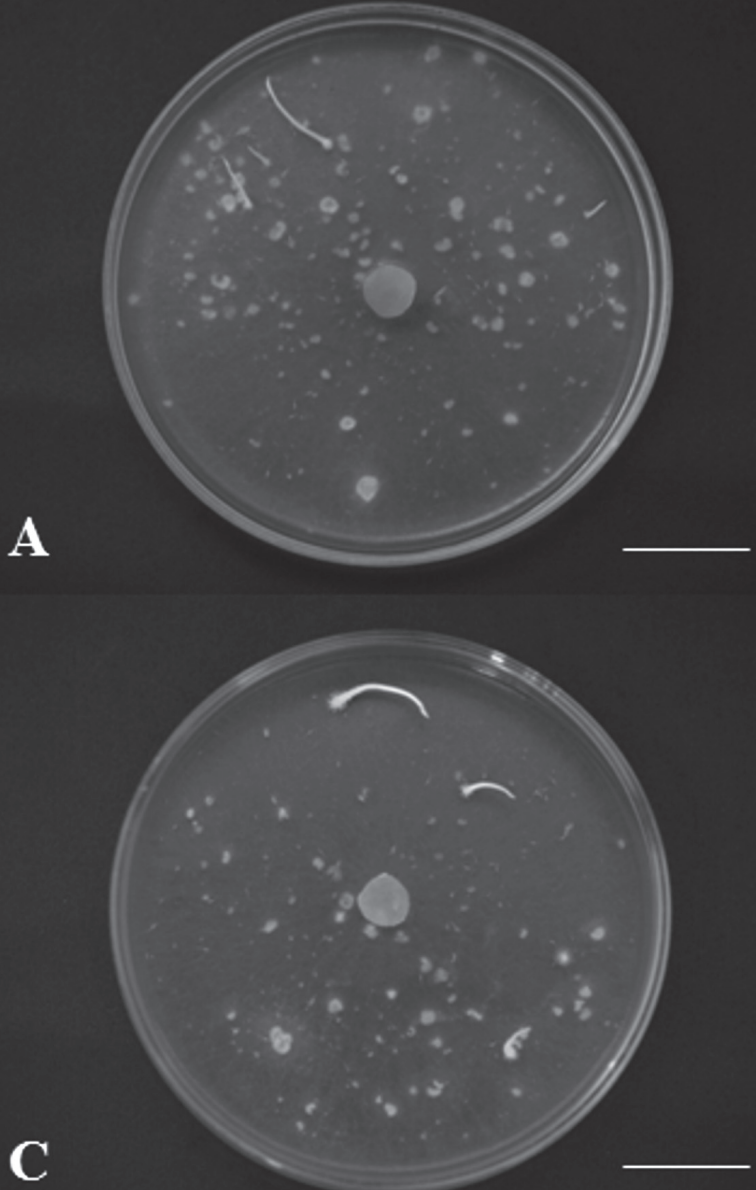

C

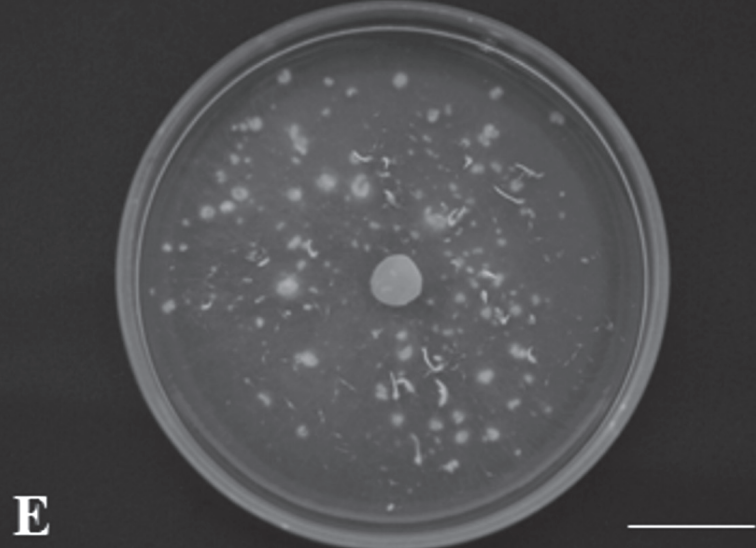

B

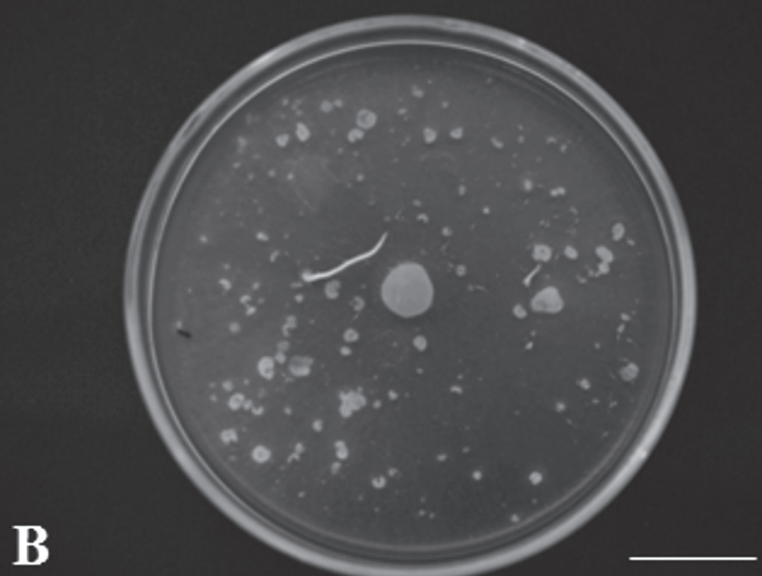

D

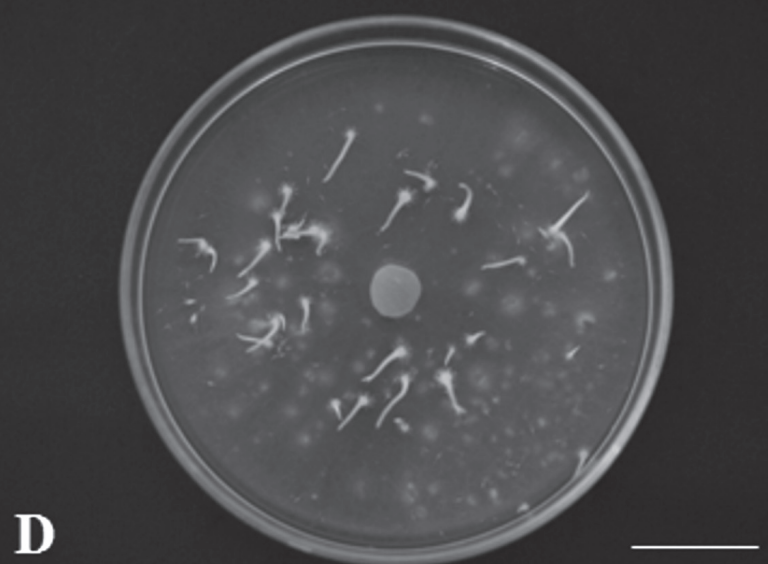

$\mathbf{F}$

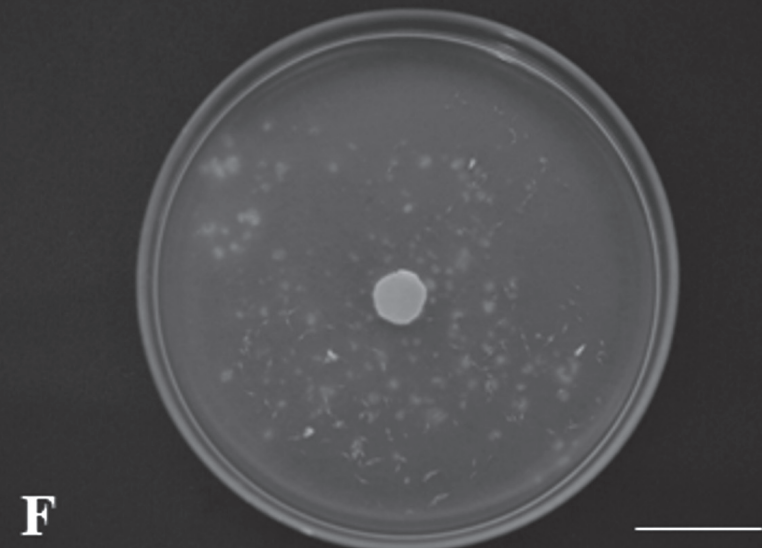

Figura 2. Protocormos de Epidendrum secundum aos 68 dias após a inoculação com diferentes isolados de fungos Epulorhiza spp e cultivados em meio aveia, na ausência de luz. Protocormos inoculados com os isolados M52 (A), M54 (B), M62 (C), M65 (D), M73 (E) e M77 (F). Barra: 2 cm.

mais avançado obtido foi 4 . Com relação aos isolados com porcentagem de germinação abaixo de $10 \%$, baixas porcentagens de protocormos nos estágios 5 e 6 foram observadas na presença dos isolados M52, M54 e M62; os demais promoveram desenvolvimento dos protocórmios até o estágio 4.

A colonização das células do embrião e a formação dos pelotons não foram observadas na associação com M61, M75 e M76, pois a testa ainda envolvia o embrião. Foi possível observar apenas o crescimento micelial do isolado M61 na testa e na superfície dos rizóides (dados não apresentados).

Em geral, foi observada a colonização da região basal dos protocormos (Fig. 4A), onde pelotons degradados e intactos ocupavam parte do volume das células corticais (Fig. 4B, C). Observou-se o crescimento de hifas na superfície e no 


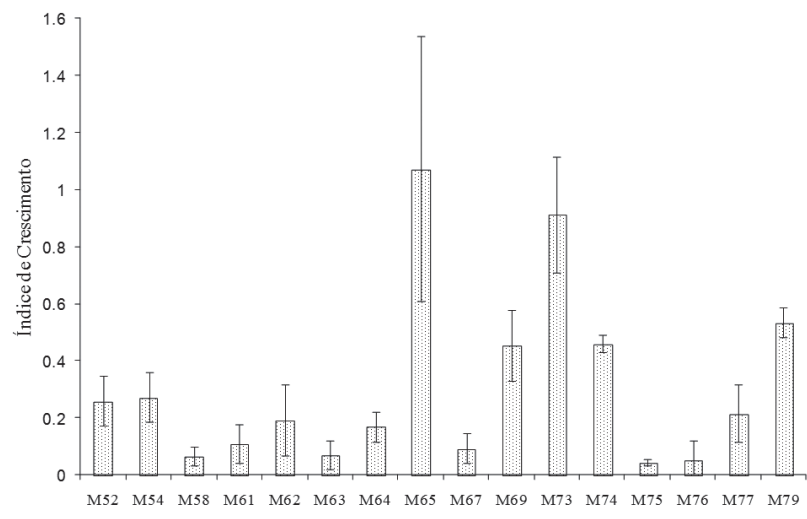

Figura 3. Índice de crescimento dos protocormos aos 44 dias após a inoculação de sementes de Epidendrum secundum com isolados de fungos rizoctonióides Epulorhiza spp. e cultivados em meio aveia na ausência de luz. Os resultados estão apresentados em média \pm desvio padrão.

interior dos rizóides (Fig. 4D, E), assim como a formação de células monilióides no seu interior dos rizóides (Fig. 4E). As células corticais, na base dos rizóides, apresentavam pelotons que possuíam conexão com as hifas observadas na região intracelular dos rizóides (Fig. 4D). Pelotons intactos foram observados na região cortical mais próxima à epiderme, enquanto os pelotons degradados se concentravam na porção mais interna desse tecido cortical (Fig. 4C, F). Os rizóides da região apical do protocormo apresentaram colonização superficial, mas não foram observadas hifas intracelulares, nem colonização das células corticais da base destes rizóides.

\section{Discussão}

As sementes de Epidendrum secundum germinaram na presença dos diferentes isolados de Epulorhiza spp. obtidos das cinco populações dessa orquídea (Fig. 1 e 2). Fungos rizoctonióides desse gênero também promoveram a germinação simbiótica de sementes de outras orquídeas, como Epidendrum conopseum R. Br. (Zettler et al. 1998), Encyclia tampensis (Lindl.) Small (Zettler et al. 1999), Goodyera pubescens (Wild.) R. Br. (Zettler \& McInnis 1993), Habenaria macroceratitis Willd. (Stewart \& Zettler 2002; Stewart \& Kane 2006), Habenaria repens Nutt. (Stewart \& Zettler 2002), Platanthera clavellata (Michx.) Luer (Zettler \& Holfer 1998), Platanthera integrilabia (Correll) Luer (Zettler \& McInnis 1992; 1994), Platanthera praeclara Sheviak \& M.L. Bowles (Sharma et al. 2003), Spiranthes brevilabris Lindley (Stewart \& Kane 2007), Spiranthes cernua (L.) L.C. Rich (Zettler \& McInnis 1993).

Para utilização dos fungos micorrízicos na produção simbiótica de mudas é importante testá-los quanto à eficiência em promover a germinação e o desenvolvimento das orquídeas, uma vez que variações nessa eficiência podem ser observadas entre isolados de uma mesma espécie e entre isolados de diferentes espécies de um gênero (Rasmussen 2002; Stewart \& Kane 2006). Os isolados testados neste trabalho apresentaram diferença na eficiência em promover a germinação das sementes e o desenvolvimento dos protocormos de E. secundum (Fig. 1 ,2). Os isolados M65 e M73 podem ser considerados os mais eficientes dentre os fungos testados, destacando-se o isolado M65 por produzir protocormos em estágios mais avançados de desenvolvimento. Os demais isolados apresentaram índice de crescimento abaixo de 0,6 e podem ser considerados de baixa eficiência.

Variações nas porcentagens de sementes germinadas e dos diferentes estágios de desenvolvimento dos protocormos foram também observadas em decorrência da inoculação de sementes de $P$. clavellata, $H$. macroceratitis e $H$. repens com isolados de Epulorhiza spp. (Zettler \& Holfer 1998; Stewart \& Zettler 2002; Stewart \& Zettler 2002; Stewart \& Kane 2006). Sementes viáveis de $H$. macroceratitis germinaram na presença de seis isolados de Epulorhiza spp., sendo as maiores porcentagens observadas quando inoculadas com fungos obtidos da população de onde as sementes foram coletadas (Stewart \& Kane 2006).

A especificidade na associação do fungo micorrízico e da orquídea precisa ser considerada durante a seleção dos isolados a serem utilizados na germinação simbiótica das sementes (Rasmussen 2002). Os estudos têm mostrado que a especificidade é variável entre as espécies de orquídea, de forma que orquídeas de um mesmo gênero podem associarse a uma maior gama de fungos e outras com menor gama (Taylor \& Bruns 1999; Shefferson et al. 2007). Para isso se faz necessário identificar os fungos capazes de estabelecer associação com a espécie no campo e então selecionar aqueles que podem ser utilizados na propagação simbiótica dessa orquídea. Os isolados testados foram obtidos de raízes de plantas adultas amostradas no ambiente natural de $E$. secundum (Tab. 1; Pereira et al. 2009). Outros trabalhos buscaram isolar fungos presentes em protocormos e plântulas coletadas no campo ou a partir de protocormos obtidos após incubação de sementes das orquídeas de interesse no seu habitat natural (McKendrick et al. 2002; Pereira et al. 2005a).

As sementes de algumas espécies de orquídeas têm germinado apenas na presença de um fungo isolado dessa espécie no campo (Zettler et al. 1998; Pereira et al. 2005c). Porém, alguns trabalhos mostram fungos micorrízicos em associação com sementes de orquídeas que não são suas hospedeiras nos ambientes naturais (Zettler et al. 1999). Segundo Hadley (1970), nos testes de germinação in vitro, as sementes de orquídeas podem se associar com uma gama de simbiontes diferente daquela observada no sistema radicular e em protocormos amostrados nos ambientes naturais. Isso sugere que não existe especificidade absoluta entre o fungo e o seu hospedeiro e que há um baixo grau de especificidade nas associações micorrízicas em orquídea. Dessa forma, os fungos micorrízicos de E. secundum avaliados neste trabalho poderiam ser aplicados na germinação simbiótica de outras espécies de orquídeas.

Os isolados das populações I e II resultaram em menor porcentagem de germinação e promoveram o desenvolvi- 


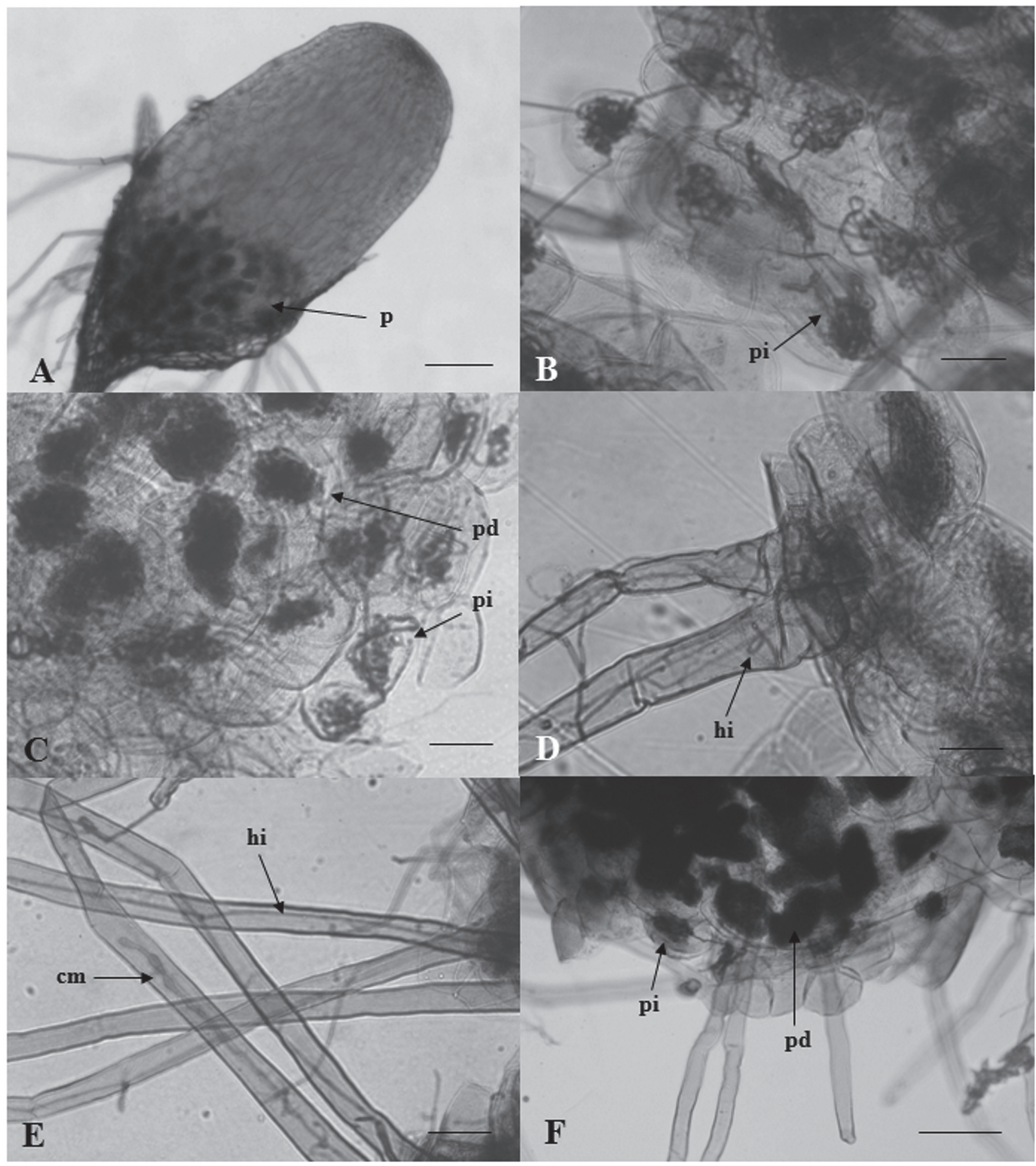

Figura 4. Colonização das células dos protocormos de Epidendrum secundum por fungos Epulorhiza spp. Base do protocormo colonizada pelo isolado M73 (A). Pelotons intactos e degradados observados em protocormos inoculados pelos isolados M63(B) e M52(C). Rizóides de protocormos colonizados pelos isolados M73 (D) e M52 (E). Cordão de pelotons intactos formados na região sub-epidérmica do córtex de protocormo colonizado pelo isolado M67 (F). cm, célula monilióide; hi, hifa intracelular; p, pelontons; pd, pelotons degradados e pi, pelotons intactos. Barras: $250 \mu \mathrm{m}(\mathrm{A}), 120 \mu \mathrm{m}(\mathrm{F}), 50 \mu \mathrm{m}(\mathrm{B}, \mathrm{D}$ e E) e $25 \mu \mathrm{m}(\mathrm{C})$.

mento até a formação da segunda folha (Fig. 1). Por outro lado, os isolados da população III promoveram maior porcentagem de germinação, mas o desenvolvimento dos protocormos foi somente até o início da formação da primeira folha. Comparando as taxas de crescimento dos isolados das três populações, Pereira et al. (2009) verificaram que todos os fungos isolados das populações I e II, com exceção de M61, crescem até três vezes mais que todos os isolados obtidos da população III. Isso explicaria porque, na presença do isolado M73, os protocormos se desenvolveram mais lentamente que na presença de M65 (Fig. 1). Essas informações sugerem que fungos compatíveis, com maiores taxas de crescimento, podem possibilitar o desenvolvimento mais acelerado dos protocormos. 
Alguns isolados fúngicos podem possuir uma maior capacidade de estimular o desenvolvimento simbiótico de orquídeas (Hadley 1970; Otero et al. 2005). Entre os isolados testados, os fungos de um mesmo grupo (Tab. 1), mesmo sendo morfologicamente iguais, promoveram a germinação sementes e desenvolvimento de protocórmios em diferentes porcentagens. Dentre os isolados do grupo B, se destacou o M73, e no grupo C, M65 (Fig. 1, 2 e 3). Esses isolados podem ser de potencial aplicação em programas de produção simbiótica de mudas de orquídea.

Variações intra-específicas existentes entre os isolados fúngicos, assim como entre as populações de uma espécie de orquídea, podem interferir no sucesso da associação micorrízica. Em algumas espécies de orquídea, os fungos promovem mais eficientemente a germinação e desenvolvimento das sementes oriundas da população de onde foi obtido (Otero et al. 2005; Stewart \& Kane 2006). O acelerado desenvolvimento dos protocormos colonizados pelo isolado M65 poderia ser explicado pelo fato desse isolado e as sementes serem oriundos da população II. Contudo, o isolado M73 promoveu alta porcentagem de germinação e com um maior tempo de incubação poderia promover altas porcentagens de protocormos no estágio 6. Experimentos in vitro de germinação simbiótica, coinoculando fungos e sementes de população deferentes, assim como experimentos ex vitro, incubando sementes em áreas diferentes da população de origem, precisam ser realizados para melhor compreensão do efeito da variação intra-específica dos diferentes fungos e populações sobre a germinação das sementes e desenvolvimento dos protocormos e plântulas.

Os resultados de Pereira et al. (2009) e do presente trabalho sugerem que a larga distribuição de E. secundum no Parque Estadual da Serra das Cabeças se deve sua habilidade em interagir a uma ampla variedade de simbiontes do gênero Epulorhiza. Os fungos desse gênero são saprófitas e podem ser encontrados em diversos ambientes (Rasmussen 2002). Se um maior número de populações dessa orquídea for estudado, outros diferentes grupos de Epulorhiza spp. poderão ser identificados e fungos micorrízicos provenientes dos diversos ambientes colonizados por essa orquídea serão obtidos. Da mesma forma, isolados de outros gêneros de fungos, obtidos de orquídeas da subtribo Laeliinae, têm apresentado efeitos positivos no crescimento de mudas dos seus hospedeiros (Ovando et al. 2005). Isso é um indicativo que mais esforços devem ser investidos para identificação de outros fungos endofíticos de E. secundum.

A manutenção dos fungos micorrízicos e endofíticos em uma coleção pode ser útil para buscar fungos com potencial utilização na propagação simbiótica de outras espécies de orquídeas. Nesse sentido, E. secundum será um importante modelo para compreensão da ecologia da associação micorrízica em orquídea.

\section{Agradecimentos}

Ao Instituto Estadual de Florestas, pela autorização de coleta na área de conservação do Parque Estadual da Serra do Brigadeiro - MG. Ao CNPq, pelo financiamento do projeto 470443/2006-5 e pelas bolsas de pesquisas.

\section{Referências bibliográficas}

Cameron, D.D.; Leake, J.R. \& Read, D.J. 2006. Mutualistic mycorrhiza in orchids: evidence from plant-fungus carbon and nitrogen transfers in the green-leaved terrestrial orchid Goodyera repens. New Phytologist 171: 405-416.

Cameron, D.D.; Johnson, I.; Leake, J.R. \& Read, D.J. 2007. Mycorrhizal acquisition of inorganic phosphorus by the green-leaved terrestrial orchid Goodyera repens. Annals of Botany 99: 831-834.

Cameron, D.D.; Johnson, I.; Leake, J.R. \& Read, D.J. 2008. Giving and receiving: measuring the carbon cost of mycorrhizas in the green orchid, Goodyera repens. New Phytologyst 180: 176-184.

Dearnaley, J.D.W. 2007. Further advances in orchid mycorrhizal research. Mycorrhiza 17: 475-486.

Dixon, K. 1987. Raising terrestrial orchids from seed. Pp.47-100. In: Harris, W.K. (Ed.) Modern orchid growing for pleasure and profit. Orchid Club of South Australia Inc.

Freudenstein, J.V.; van den Berg, C.; Goldman, D.H.; Kores, P.J.; Molvray, M. \& Chase, M.W. 2004. An expanded plastid DNA phylogeny of Orchidaceae and analysis of jackknife branch support strategy. American Journal of Botany 91: 149-157.

Hadley, G. 1970. Non-specificity of simbiotic infection in orchid mycorrhiza. New Phytologist 69: 1015-1023.

Massey, E.E. \& Zettler, L.W. 2007. An expanded role for in vitro symbiotic seed germination as a conservation tool: two case studies in North America (Platanthera leucophaea and Epidendrum nocturnum). Lankesteriana 7(1-2): 303-308.

McCormick, M.K.; Whigham, D.F. \& O’Neill, J. 2004. Mycorrhizal diversity in photosynthetic terrestrial orchids. New Phytologist 163: 425-438.

McKendrick, S.L.; Leake, J.R.; Taylor, D.L. \& Read, D.J. 2002. Symbiotic germination and development of the myco-heterotrophic orchid Neottia nidus-avis in nature and its requirement for locally distributed Sebacina spp. New Phytologist 154: 233-247.

Nogueira, R.E.; Pereira, O.L.; Kasuya, M.C.M.; Lanna, M.C. \& Mendonça, M. 2005. Fungos micorrízicos associados e orquídeas em campos rupestres na Região do Quadrilátero Ferrífero, Minas Gerais, Brasil. Acta Botanica Brasilica 3: 417-424.

Otero, J.T.; Bayman, P. \& Ackerman, J.D. 2005. Variation in mycorrhizal performance en the epiphytic orchid Tolumnia variegata in vitro: the potential for natural selection. Evolutionary Ecology 19: 29-43.

Ovando, I.; Damon, A.; Bello, R.; Ambrosio, D. Albores, V. Adriano, L. \& Salvador, M. 2005. Isolation of endophytic fungi and their mycorrhizal potential for the tropical epiphytic orchids Cattleya skinneri, C. aurantiaca and Brassavola nodosa. Asian Journal of Plant Sciences 4(3): 309-315.

Pereira, O.L.; Rollemberg, C.L. \& Kasuya, M.C.M. 2002. Associações micorrízicas em orquídeas: perspectivas e utilização em programas de propagação simbiótica. Orquidário 16(2): 40-44

Pereira, O.L.; Kasuya, M.C.M.; Borges, A.C. \& Araújo, E.F. 2005a. Morphological and molecular characterization of mycorrhizal fungi isolated from neotropical orchids in Brazil. Canadian Journal of Botany 83: 54-65.

Pereira, O.L.; Kasuya, M.C.M.; Rollemberg, C.L. \& Borges, G.M. 2005b. Isolamento e identificação de fungos micorrízicos rizoctonióides associados a três espécies de orquídeas epífitas neotropicais no Brasil. Revista Brasileira de Ciência do Solo 29: 191-197.

Pereira, O.L.; Kasuya, M.C.M.; Rollemberg, C.L. \& Borges, A.C. 2005c. Indução in vitro da germinação de sementes de Oncidium flexuosum (Orchidaceae) por fungos micorrízicos rizoctonióides. Revista Brasileira de Ciência do Solo 29: 199-206. 
Pereira, M.C.; Kasuya, M.C.M.; Pereira, O.L.; Costa, M.D. \& Rocha, R.B 2009. Diversidade de fungos micorrízicos Epulorhiza spp. isolados de Epidendrum secundum (Orchidaceae). Revista Brasileira de Ciência do Solo 33: 1187-1197.

Peterson, R.L.; Massicotte, H.B. \& Melville, L.H. 2004. Mycorrhizas: anatomy and cell biology. NRC Research Press.

Phillips, J.M. \& Hayman, D.S. 1970. Improved procedure for clearing roots and staining parasitic and vesicular-arbuscular mycorrhizal fungi for rapid assessment of infection. Transaction of the British Mycological Society 55: 158-161.

Pinheiro, F. \& Barros, F. 2007. Epidendrum secundum Jacq. e E. denticulatum Barb. Rodr. (Orchidaceae): caracteres úteis para a sua delimitação. Hoehnea 34(4): 563-570.

Rasmussen, H.N. 1995. Terrestrial orchid: from seed to mycotrophic plant. Cambridge, Cambridge University Press.

Rasmussen, H.N. 2002. Recent developments in the study of orchid mycorrhiza, Plant and Soil 244: 149-163.

Smith, S.E. \& Read, D.J. 1997. Mycorrhizal Symbiosis. 2.ed. Academic Press.

Shan, X.C.; Liew, E.C.; Weatherhead, M.A. \& Hodkiss, L.J. 2002. Characterization and taxonomy placement of Rhizoctonia-like endophytes from orchid roots. Mycologia 94(2): 230-239.

Sharma, J.; Zettler, L.W.; van Sambeek, J.W.; Ellersieck, M.R. \& Starbuck, C.J. 2003. Symbiotic seed germination and mycorrhizae of federally threatened Platanthera praeclara (Orchidaceae). The American Midland Naturalist 149(1): 104-120.

Shefferson, R.P.; Taylor, D.L.; Weiß, M.; Garnica, S.; et al. 2007. The evolutionary history of mycorrhizal specificity among lady's slipper orchids. Evolution 61(6): 1380-1390.

Stewart, S.L. \& Zettler, L.W. 2002. Symbiotic germination of three semiaquatic rein orchids (Habenaria repens, H. quinquiseta, H. macroceratitis) from Florida. Aquatic Botany 72: 25-35.

Stewart, S.S. \& Kane, M.E. 2006. Symbiotic seed germination of Habenaria macroceratitis (Orchidaceae), a rare Florida terrestrial orchid. Plant Cell Tissues and Organ Culture 86: 159-167.

Stewart, S.L. \& Kane, M.E. 2007. Symbiotic seed germination and evidence for in vitro mycobiont specificity in Spiranthes brevilabris (Orchidaceae) and its implications for species-level conservation. In Vitro Cellular \& Developmental Biology - Plant 43:178-186.
Taylor, D.L. \& Bruns, T.D. 1999. Population, habitat and genetic correlates of mycorrhizal specialization in the 'cheating' orchids Corallorhiza macula and C. mertensiana. Molecular Ecology 8: 1719-1732.

van den Berg, C.; Higgins, W.E.; Dressler, R.L.; Whitten, W.M.; Arenas, M.A.S.; Culhan, A. \& Chase, M.W. 2000. A phylogenetic analysis of Laeliinae (Orchidaceae) based on sequence data from internal transcribed spacer (ITS) of nuclear ribosomal DNA. Lindleyana 15: 96-114.

van den Berg, C.; Goldman, D.H.; Freudenstein, J.V.; Pridgeon, A.M.; Cameron, K.M. \& Chase, M.W. 2005. An overview of the phylogenetic relationships within Epidendroideae inferred from multiple DNA regions and recircumscription of Epidendreae and Arethuseae (Orchidaceae). American Journal of Botany 92: 613-624.

Zettler, L.W. 1997. Terrestrial orchid conservation by symbiotic seed germination: techniques and perspectives. Selbyana 18: 188-194.

Zettler, L.W. \& McInnis, T.M. Jr. 1992. Propagation of Platanthera integrilabia (Correll) Luer, an endangered terrestrial orchid, through symbiotic seed germination. Lindleyana 7: 154-161.

Zettler, L.W. \& McInnis, T.M. Jr. 1993. Symbiotic seed germination and development of Spiranthes cernua (L.) L.C. Rich and Goodyera pubescens (Wild.) R. Br. (Orchidaceae: Spiranthoideae). Lindleyana 8: $155-162$.

Zettler, L.W. \& McInnis, T.M. Jr. 1994. Light enhancement of symbiotic seed germination and development of an endangered terrestrial orchid (Platanthera integrilabia). Plant Science 102: 133-138.

Zettler, L.W. \& Hofer, C.J. 1998. Propagation of the little club-spur orchid (Platanthera clavellata) by symbiotic seed germination and its ecological implications. Enviromental and Experimental Botany 39: 189-195.

Zettler, L.W.; Delaney, T.W. \& Sunley, J.A. 1998. Seed propagation of epiphytic green-fly orchid, Epidendrum conopseum R. Brown, using its endophytic fungus. Selbyana 19: 249-253.

Zettler, L.W.; Burkhead, J.C. \& Marshall, J.A. 1999. Use of a mycorrhizal fungus from Epidendrum conopseum to germinate seed of Encyclia tampensis in vitro. Lindleyana 14: 102-105.

Zettler, L.W.; Sharma J. \& Rasmussen, F. 2003. Mycorrhizal Diversity. Pp. 185-203. In: Dixon, K. Cribb, P. Kell, S. Barrett, R. (Eds), Orchid Conservation. Natural History Publications, Kota Kinabalu, Sabah, Malaysia. 